\title{
Diverse Influences on Parachuting Injuries in Israel
}

\author{
Yosefa Bar-Dayan, Yaron Bar-Dayan, Moshe Weisbroth, Joshua Shemer
}

\begin{abstract}
Background

Parachuting is known to be relatively safe and has a low injury rate. There are some parameters influencing parachuting casualties. In order to determine the influences of type of jump and parachute, effect of equipment carried, time of jump and wind speed, we conducted a retrospective study at the Parachuting Training Center of Israel, assessing 53832 military parachute jumps.
\end{abstract}

\section{Methods}

Two categories of injuries were defined: major (fractures, dislocation, head trauma, ligamentous tears) and minor (contusion, bruises, sprain injuries).

\section{Results}

The overall injury rate was 0.6 percent. The commonest major injuries were ankle fractures and head trauma, while ankle sprain was the most common minor injury. The lowest rate of injury was found in free falls jumpers $(0.2$ percent) and highest amongst manoeuvres (1.1 percent). The highest injury rate occurred when using an Israeli version of " $\mathrm{T}-10$ " military parachute $(0.7$ percent) and the lowest with free fall parachutes $(0.2$ percent). Extra equipment carried during jumps caused higher injury rate ( 0.8 percent) compared to jumps without equipment ( 0.5 percent) using the " $\mathrm{T}-10$ " military parachute. Injury rates were greater at night (1.0 percent) compared to day jumps ( 0.5 percent). In day jumps commonest major injury was ankle fracture, while in night jumps it was head trauma. The commonest minor injury in day and night jumps was ankle sprain. At wind speed of 0-4 Knots parachuting injuries were higher compared with wind speeds of 5-8, 9-12 and 13-16 Knots with injury rates of 0.8, 0.5 and 0.6 percent respectively.

\section{Conclusions}

Diverse factors influence the injury rate in parachuting. Identifying such factors may enable us to change them in order to minimize the number of injured parachutists.
Keywords:

parachuting injuries, ankle sprain, ankle fracture, head trauma, environmental influences.

\section{Introduction}

The majorities of parachuting injuries affect the lower extremities and vertebral bodies, and are attributed to poor parachuting or landing techniques (1-4).

The risk of parachuting injury is relatively low and injury rates are estimated at 0.31 1.4 percent $(1,5,6,8,9,10)$.

The injury rate of parachuting is influenced by parameters such as the type of parachute used and jump technique, equipment carried during the jump, wind speed, temperature, ground conditions, whether the jump was performed by day or by night, and the experience of the parachutist $(2,7)$.

In order to determine the importance of these factors on parachuting injuries in our center we examined retrospectively some of these factors and their influence on parachuting casualties at the Training Center of Parachuting in Israel.

\section{Materials and Methods}

The casualties of 53832 military parachute jumps trained at the Training Center of Parachuting, Israel, were recorded.

The jumpers consisted of male soldiers doing the basic course in order to learn how to parachute and male paratroopers doing refresher jumps with their units. Parachuting instructors were responsible for only a small portion of the jumps performed.

The data was collected from accident reports, flight manifest and drop reports. Accident reports were mandatory completed for any parachuting injury. Practically all the injured parachutists during the course did not continue it and some of them participated in the following courses.

The accident reports were filed by a physician and included the diagnosis, the drop zone and circumstances of the injury. When a specialist consults or hospital admission were necessary, contact was made to verify the diagnosis.

The casualties taken into account refer to all kind of injuries, including static line failures and entanglements, equipment failures, mid-air collisions and injuries on landing. Two categories or injuries were defined: major and minor. Major injuries 
included all fractures, dislocations, head injuries and ligamentous tears. Contusions, bruises and sprains were classified as minor injuries $(1,8,9,10)$.

The flight manifest reported the name of the person dropped, the type of parachute and equipment used, and finally the time of jumps (day or night). The Jump report noted the wind speed recorded during the drop as well as the name of the person who required medical assistance after the jump and whether he was admitted to a hospital or to other medical care.

The majority of jumps were made with an Israeli version of T-10 ("T-10"), a standard ordinary military parachute opened by static line and not steerable. The minority were made with sport parachutes of various types, steerable and opened after free fall by ripcord, and with $\mathrm{MC}-1-1-\mathrm{B}$ a military parachute which is opened by static line and is steerable (Table 1). All the jumps took place from C-130 Hercules aircraft.

Using the flight manifest sheets the jumps were classified according to the time of jump. When a jump took place 1 hour after sunset it was considered as a night jump.

Experienced land officers measured wind speed at ground level using a special device for wind measurement, and it refers to maximum wind speed during the drop. 4 subclasses were defined: 0-4, 5-8, 9-12 and 13-16 knots (Kn.).

In order to establish any correlation between the different parameters, the number of casualties: major and minor, were counted according to each parameter. The correlation was examined using the Chi square test.

Table 1. Technical data of the parachutes

\begin{tabular}{lll}
\hline Characteristic & "T-10”* & $M C-1-1-B$ \\
\hline Weight (kg) & 14.1 & 14.1 \\
Skirt diameter (m) & 10.7 & 10.7 \\
Apex hole diameter (m) & 0.5 & 0.1 \\
Canopy cloth type & Nylon & Nylon \\
No. of gores & 30.0 & 30.0 \\
No. of panels per gore & 5.0 & 5.0 \\
Canopy height & 5.30 & 5.50 \\
Surface area (m2) & 84.0 & 84.0 \\
^”T-10”-An Israeli version of T-10 parachute.
\end{tabular}

\section{Results}

Our data enables us to compare the different parameters using the parachuting injury rate of major and minor casualties together.

The injury rate of 53832 jumps was 0.6 percent. Only one third of all casualties were considered as major injuries. Death was not reported during all the years the study took place.

The most frequent major injuries were ankle fractures and head trauma, while ankle sprain was the commonest minor injury.

The injury rate was different for the diverse types of jumps. Lowest rate was found for free fall jumpers (0.2 percent) and highest for jumps during manoeuvres (1.1 percent) (Table 2).

The rate of injury in parachutists using " $\mathrm{T}$ -
Table 2. Summary of injury rates according to type of jumps

\begin{tabular}{lllll}
\hline Type of jump & $\begin{array}{l}\text { No. of } \\
\text { fumps }\end{array}$ & $\begin{array}{l}\text { No. } \\
\text { Injured }\end{array}$ & Rate & $\begin{array}{l}\text { P (two } \\
\text { sided) }\end{array}$ \\
\hline Basic Course & 37230 & 222 & 0.6 & $\begin{array}{l}1 \\
<0.0001\end{array}$ \\
Manouevres & 10093 & 109 & 1.1 & ${ }^{2} 0.02$ \\
Refresher & 1112 & 4 & 0.4 & ${ }^{3} 0.31$ \\
Free Jumps & 1951 & 4 & 0.2 & \\
"T-10" & 49754 & 335 & 0.7 & ${ }^{4} 0.01$ \\
MC-1-1-B & 2667 & 7 & 0.3 & \\
Free Fall & 1301 & 3 & 0.2 & ${ }^{5}>0.85$ \\
& & & & \\
Without Equipment & 27324 & 136 & 0.5 & $<0.0001$ \\
Extra Equipment & 26501 & 209 & 0.8 &
\end{tabular}

Comparison between injury rates of basic course and manouevres

Comparison between injury rates of manouevres and refresher jumps

Comparison between injury rates of basic course and refresher jumps

Comparison between injury rates of "T-10" and $\mathrm{MC}-1$ $1-B$

Comparison between injury rates of $M C-1-1-B$ and free fall

* Data concerning other type of jumps, parachutes and equipment were not considered in our study.

Table 3. Summary of injury rates according to time of jumps

\begin{tabular}{lllll}
\hline Type of jump & $\begin{array}{l}\text { No. of } \\
\text { fumps }\end{array}$ & $\begin{array}{l}\text { No. } \\
\text { Injured }\end{array}$ & Rate & $\begin{array}{l}P \text { (two } \\
\text { sided) }\end{array}$ \\
\hline Day & 36074 & 169 & 0.5 & $<0.00001$ \\
Night & 17758 & 176 & 1.0 & \\
\hline
\end{tabular}

Table 4. Summary of injury rates according to wind speed

\begin{tabular}{lllll}
\hline Wind Speed & $\begin{array}{l}\text { No. of } \\
\text { fumps }\end{array}$ & $\begin{array}{l}\text { No. } \\
\text { Injured }\end{array}$ & Rate & $\begin{array}{l}P \text { (two } \\
\text { sided) }\end{array}$ \\
\hline 0-4 Kn. & 233 & 184 & 0.8 & ${ }^{1} 0.003$ \\
5-8 Kn. & 16964 & 90 & 0.5 & ${ }^{2} 0.002$ \\
9-12 Kn. & 12706 & 66 & 0.5 & ${ }^{3} 0.003$ \\
$13-16 \mathrm{Kn}$. & 839 & 5 & $0 / 6$ & ${ }^{4} 0.5$
\end{tabular}

13-16 Kn. $839 \quad$ Comparison between injury rates of wind speed of $0-4$ Kn., and the other 3 wind speeds: 5-8, 9-12 and 13-16 $\mathrm{Kn}$.

Comparison between injury rates of wind speed of 0-4 $\mathrm{Kn}$., and 5-8 Kn.

Comparison between injury rates of wind speed of 0-4 $\mathrm{Kn}$ and 9-12 Kn.

Comparison between injury rates of wind speed of 0-4 $\mathrm{Kn}$ and 13-16 Kn., comparison between injury rates of wind speed of 5-8, 9-12 and 13-16 Kn., gave a P value of 0.95 .

10" was 0.7 percent, with MC-1-1-B 0.3 percent and only 0.2 percent with a free fall parachute. The injury rate was significantly higher in "T-10" group compared to the others $(p=0.03)$. No significant difference was found between MC-1-1-B and a free fall parachutes (Table 2).

When the jumps took place with extra equipment such as chest bag (weight $20-30$ $\mathrm{Kg}$ ) using a "T-10" parachute the injury rate was 0.8 percent, and it was significantly higher compared to jumps without extra equipment with an injury rate of 0.5 percent $(\mathrm{p}<0.0001)$ (Table 2).

The injury rate for day jumps was 0.5 percent and for night jumps 1.0 percent $(p<0.00001)$ (Table 3). The commonest major injury in day jumps was ankle fractures and in night jumps head trauma, while the most common minor injury in both day and night jumps was ankle sprain.

The injury rate for the four subclasses of wind speed: 0-4 Kn., 5-8 Kn., 9-12 Kn., 13- 
$16 \mathrm{Kn}$., was $0.8,0.5,0.5$ and 0.6 respectively. Only the subclass with the wind speed of 0-4 $\mathrm{Kn}$., had significantly higher injury rate compared to the others $(\mathrm{P}<0.005)$ (Table 4$)$.

\section{Discussion}

In our study the mean injury rate was 6 per 1000 plane jumps, compared to injury rates of 3.1 - 14 per 1000 jumps published elsewhere $(1,7,9,10,11)$. Difference in the definition of parachuting injuries is probably one of the most important factors that make the comparison between injury rates of parachuting centers difficult.

The most common involved area was the ankle joint. It is well recognized that by far the majority of parachuting injuries occur on landing. As the lower extremities absorb the initial impact on landing the ankle joint is the part of the body most frequently injured $(1,3,5,8,9,10)$. In comparison head injury is mainly due to backward landing (11).

Night jumps are associated with higher rates of injuries than day jumps, using the same type of parachutes. The proportions of jumps using "T-10" and MC-1-1-B were the same in day and night. There is no doubt that the conditions are at least favourable at night jumps. Due to the darkness the parachutist may experience some feelings of spatial disorientation and find it more difficult to estimate distances and avoid obstacles such as rocks and bushes on landing.

It is interesting to note the differences between day and night jumps regarding major injuries. In day jumps, most are fractures, while for night jumps head trauma.

Several explanations can be forwarded to account for this observation. At night the parachutist feels disorientated and may have difficulties in estimating the distance between his head and legs. In addition, he may be unable to evaluate accurately the distance between himself and the ground and thus is prone to land unprepared. The resulting impact would cause him to fall backward and be at greater risk of head injury. Also in day jumps the parachutists instinctively protects his head from obstacles on landing. At night he cannot see rocks and bushes so he is less aware and less able to guard his head. Night jumps are involved with intense feelings of fear, loneliness in the drop zone, and feelings of uncertainty. Perhaps, due to these feelings parachutists tend to go to the doctor even if they suffered minimal trauma. The doctor, due to the condition under which he examines the soldier i.e., darkness and difficulties in assessing the injured body tends to exacerbate his findings, and diagnoses head trauma until proved otherwise to avoid the possibility of making a wrong diagnosis, especially concerning head injury, which can evolve gradually, without any signs immediately after the trauma.

Analysis of the injury rate in the various types of jumps shows that the injury rate was significantly lower amongst free jumpers. This is not new $(6,10)$, and is due to the high qualification of these parachutists. The injury rates were relatively low during both basic course and refresher jumps. No significant difference was observed between the injury rates in these groups. However in manoeuvres there was a significantly higher injury rate compared to basic course and refresher jumps.

These observations are not surprising. There is a bias for light injuries during manoeuvres. In the basic course the soldier will tend to hide his injury, because of fear of being grounded and not being able to finish the course and gain the parachuting wings. During manoeuvres the parachuting is usually the first stage of military exercise, and it proceeds by intensive strenuous physical exertion, often throughout the night. This results in both true reporting and some over reporting of light injuries (10).

Interesting to note that we did not find a significant difference between the injury rate in the basic course compared to refresher jumps. This is probably due to the low numbers of refresher jumps, thus making meaningful statistical comparison not possible.

A comparison made between the injury rate of two types of parachutes " $\mathrm{T}-10$ " and MC-1-1-B showed significant differences between them, although both have the same size of canopy (Table 1). These differences can be explained by the fact that at our center only the parachuting instructors jump with MC-1-1-B, while all the others parachutists (basic course, refresher and manoeuvre) jump with the "T-10". The parachuting instructors are the most qualified and jump very frequently compared to the other groups. No significant differences was found between injury rate of MC-1-1-B and free fall parachutes, this is probably due to the low number of these jumps, again making meaningful statistical comparison not possible.

Using the same type of parachute, a significant difference in rate injury was observed between the jumps with extra equipment. The kinetic energy of parachutist during the descent is proportional to total mass and velocity [Force $\left.=0.5 \mathrm{mv}^{2}\right]$ (7). As the total mass grows the kinetic energy increases and the landing impact and the risk of injury become greater (3).

We consider our most important observation to be that regarding wind speed. In contrast to what is known in literature (7), we observed that wind speed of 0-4 Knots aggravates parachuting injuries more than a higher wind speed. This observation is known intuitively to veteran parachuting instructors, who say that to perform rolling effectively, there must be some ground wind. However, since the number of jumps in the 
group with wind speed of 13-16 Kn., was small, a statistical analysis of comparison between these groups would not be meaningful.

Due to the retrospective nature of this study, only a few of the variables that may be relevant for parachuting injuries were examined. Other parameters that may have had some influence on parachuting injuries were not included. A prospective study should be undertaken in order to gather better information about the influence of a specific parameter on defined parachuting injury.

\section{Acknowledgement}

We are indebted to Mr. Giat Avraham for his assistance in management and analysis of data.

\section{References}

1. Lowdon IMR, Wetherill MH: Parachuting injuries during training descent. Injury 1989; 20 (5): 257258.
2. Charles C, Baldwin MD: Parachuting injuries and type of parachute in a reserve rescue unit. Aviat Space Environ Med 1988; 8: 780-782.

3. Ellisgaard N, Warburg F: Movements causing ankle fractures in parachuting. Br $\mathcal{F} S p$ Med 1989; 23(1): 27-29.

4. Mellen PF: Parachuting static line injury with vascular compression. Milit Med 1989; 154(7): 364-365.

5. Bar Dayan Y, Bar Dayan Y, Shemer J: Parachuting injuries: a retrospective study of 43542 military jumps. Milit Med 1998; 163(1): 1-2.

6. Mellen PF, Sohn SS: Military parachute mishap fatalities: a retrospective study. Aviat Space Environ Med 1990; Dec. 1149-1152.

7. Pirson J, Verbiest E: A study of some factors influencing military parachute landing injuries. Aviat Space Environ Med 1985; 56(6): 564-567.

8. Amamilo SC, Samuel AW, Kesketh KT, Koynihan FJ: A retrospective study of parachute injuries in civilians. F Bone ft Surg 1987; 69(B): 17-19.

9. Ellisguard $\mathrm{N}$ : Parachuting injuries: a study of 110,000 sports jumps. Br $\mathcal{F}$ Sports Med 1987; 21(1): 13-17.

10. Hallel T, Naggan L: Parachuting injuries: a retrospective study of 83,718 jumps. F Trauma; 15: 14-19, 1975.

11. Davison D.J: A review of parachuting injuries. Injury 1990; 21: 314-316. 